\title{
Factors Associated with Adherence to Antiretroviral Therapy Among People Living With HIV \& AIDS
}

\author{
Nirmala Aryal, Radha Poudel, Sarita Adhikari and Aruna Rai
}

College of Nursing, Nepalese Army Institute of Health Sciences, Bhandarkhal, Sanobharyang, Kathmandu, Nepal

\begin{abstract}
Introduction: AIDS and STD is prioritised disease control program of Nepal. Successful treatment of HIV positive patient is fundamental to control the progression to AIDS and ART adherence is crucial for successful treatment. The objective of the study was to find out the factors associated with adherence to antiretroviral therapy among people living with HIV/AIDS.

Methods: Descriptive cross sectional research design was adopted. A total of 195 people living with HIV who were above the age 18 years and taking ARV therapy for at least six months from the ART centre of Sukraraj Tropical and Infectious Disease Hospital were selected by using purposive sampling technique. Data was collected using interview technique with semi structured questionnaire. Collected data was analysed using descriptive and inferential statistics.

Results: The findings showed that $91.28 \%$ of the respondents reported perfect adherence $(\geq 95 \%)$ and $8.71 \%$ of the respondents reported non- adherence. Age (OR: 4.28; CI 1.00-18.26) and marital status (OR: 4.96; CI 1.67-14.75) were the socio-demographic factors associated with adherence to ARV therapy. Number of tablets per day (OR: 10.72; CI 1.21-94.4) and use of reminders tool (OR:11.14; CI 2.35-52.75) were the patient related factors significantly associated with the adherence to ARV therapy. Likewise, experience of no discrimination (OR 3.90; CI 1.11-13.69) and help for the intake of medicine from family members (OR 2.95; CI 1.95-9.19) were the psychosocial factors significantly associated with adherence to ARV therapy. Adherence counselling (OR 13.38; CI 2.99-59.75) and lower travelling cost (OR 3.99; CI 1.40-11.34) were the service factors significantly associated with adherence to ARV therapy.

Conclusions: The prevalence of adherence found in this study was good. Help from the family members, adherence counselling and use of reminders tool for intake of medicine enhanced adherence. Whereas, side effects, alcohol use, burden of pills, experience of discrimination were the barriers for adherence to ART. For improving adherence government and as well as the hospital requires interventions which recognise these barriers.
\end{abstract}

Keywords: Antiretroviral Therapy (ART); adherence; AIDS patient

Correspondence: Nirmala Aryal, College of Nursing, Neapalese Army Institute of Health Sciences, Bhandarkhal, Sanobharyang, Kathmandu, Nepal. E-mail: nirmalaaryal44@gmail.com

DOI: $10.3126 /$ mjsbh.v18i1.19560

Submitted on: $2018-06-07$

Accepted on: 2018-12-20 


\section{INTRODUCTION}

HIV infects people worldwide and has reached pandemic proportions in about two decades since the first report of AIDS. Since 1981, an estimated 25 million people died of AIDS and 65 million have been infected worldwide. An extremely high status of adherence is required to guarantee treatment effectiveness. A total of 6,483 HIV/AIDS clients have been benefited by antiretroviral therapy and estimated that 25,169 people are in need of therapy in Nepal. Government is providing ARV therapy freely to the clients and investing a large amount of money for providing ARV therapy because of its huge benefits to HIV/AIDS Clients. ${ }^{1}$ It is well understood and documented that HIV/ AIDS requires near perfect adherence to obtain successful treatment outcomes. Suboptimal adherence directly relates to increasing the likelihood of drug resistance and contributing to direct treatment failure. ${ }^{2}$

In Asian developing communities, the factors impeding ART adherence are financial difficulties, stigma and discrimination, simply forgetting, being too busy, concurrent substance abuse and side effects. On the other hand, self-efficacy, family support and financial assistance facilitated adherence. ${ }^{3}$ Adherence to ART in Tribhuvan University Teaching Hospital was found to be $79 \%$. The major barrier to adherence was reported to be simply forgetfulness $(33.3 \%$ of those non adherents). ${ }^{4}$

Even though availability of free antiretroviral drugs is increasing, there are still many obstacles that hinder patients to achieve good adherence to antiretroviral therapy. It is estimated that $19 \%$ of adult patients are not retained on antiretroviral therapy after 12 months in poor countries. ${ }^{5}$ In Nepal, even after decade of starting ARV therapy, studies regarding level of adherence to ARV therapy and factors associated with adherence to
ARV therapy appears to be limited. Therefore, this study was aimed to identify the level of adherence to ART and factors associated with adherence to ARV therapy among people living with HIV and AIDS.

\section{METHODS}

After approval by Institutional Review Board, formal permission was taken from the concerned academic institution. The purpose of the study was explained to the respondents and written informed consent was taken from each respondent before data collection. The study followed a descriptive cross sectional research design, conducted from the month of October 2014 to November 2014 in ART centre of the tertiary care level infectious hospital. People who were above 18 years of age and taking ART medicine for at least six months were identified through ART card and consent was taken for data collection. Data was collected using interview technique with semi structured questionnaire. In this study adherent status was categorised based on the number of doses of Antiretroviral drugs missed as adherent and nonadherent.

Adherent means less than three doses of Antiretroviral drugs missed in 30 days $(>95 \%)$. Nonadherent means three or more doses of Antiretroviral drugs missed in a period of 30 days $(\leq 95 \%) .{ }^{2}$ Multivariate analysis was conducted including all the variables of patient related factors in one model and all the variables of psychosocial and service related factors those were significant in bivariate analysis in one model. For ease in computing association, age has been later subgrouped into $\leq 38$ years and $>38$ years (i.e. above and below the mean age). Similarly, the education has been later sub-grouped into illiterate and literate. Primary education and secondary and above education have been grouped into literate group. Similarly, monthly family income has been 
later sub-grouped into Sufficient and Hardly sufficient. Sufficient and surplus have been grouped into sufficient group. Duration of illness has been sub-grouped into $\leq 24$ months and $>24$ months. Less than one year and one to two years have been sub-grouped into $\leq 24$ months and three to five years and more than five years have been sub-grouped into $>24$ months. Source of information has been sub-grouped into Health personnel and others. TV/Radio and Friends/ Relatives have been sub- grouped into others. Travelling cost has been sub-grouped into Lower cost and higher cost. $<100$ Rs and 100 to 500 Rs have been sub-grouped into Lower travelling cost and $>500$ Rs have been sub-grouped into Higher travelling cost. Time to reach ART centre (Distance to the health facility) has been sub-grouped into $\leq 60$ minutes and $>60$ minutes. 30 minutes and 31 to 60 minutes have been sub-grouped into $\leq 60$ minutes and 61 to 120 minutes and $>120$ minutes have been sub-grouped into $>60$ minutes. Waiting time in each visit has been sub-grouped into $\leq 15$ minutes and $>15$ minutes. $15-30$ minutes, 30 to 60 minutes and $>60$ minutes have been sub-grouped into $>15$ minutes.

\section{RESULTS}

Table 1 reveals that majority of the respondents $(89.2 \%)$ took medicine at right time (right dose and schedule) as prescribed i.e. optimal adherence of ARV therapy is $89.2 \%$, where $91.7 \%(n=179)$ reported perfect/good adherence ( $\geq 95 \%)$ and $8.2 \%$ $(n=16)$ of the respondents reported missing three or more than three medications during the previous month.

Table 2 shows that age was significantly associated with adherence to ARV therapy (OR 4.28; CI 1.00 to 18.26) The model was fit as shown by Hosmer and Lemeshow Test of significance $(p=0.75)$. Age group $>38$ years were 4 times more likely to report adherence to ARV therapy than those age group
Table 1. Adherence status of the Respondents $(n=195)$

\begin{tabular}{|c|c|c|}
\hline Adherence status & Frequency & Percentage \\
\hline \multicolumn{3}{|l|}{$\begin{array}{l}\text { Taking medicine at } \\
\text { right time as } \\
\text { prescribed }\end{array}$} \\
\hline Yes & 175 & 89.2 \\
\hline No & 20 & 10.2 \\
\hline \multicolumn{3}{|l|}{$\begin{array}{l}\text { If no, number of } \\
\text { dose missed in last } \\
\mathbf{3 0} \text { days }(\mathrm{n}=\mathbf{2 0})\end{array}$} \\
\hline$<3$ times $(>95 \%)$ & 4 & 2.0 \\
\hline$\geq 3$ times $(80-95 \%)$ & 16 & 8.2 \\
\hline \multicolumn{3}{|l|}{ Adherence status } \\
\hline Adherence & 179 & 91.7 \\
\hline Non- adherence & 16 & 8.2 \\
\hline
\end{tabular}

$\leq 38$ years. Whereas, marital status, monthly family income, duration of illness, initiation of ARV and source of information were not significantly associated with adherence to ARV therapy.

Table 3 shows that number of tablets used daily was significantly associated with adherence to ARV therapy ( $p=0.032$, OR 10.72; CI $1.21-94.43$ ). The model was fit as shown by Hosmer and Lemeshow Test of significance $(p=0.75)$. Those people with HIV who take three or less tablets per day were 10 times more likely to report adherence to ARV therapy than those who take more than three tablets per day. Use of remainders tool was significantly associated with adherence to ARV therapy ( $\mathrm{p}=$ 0.002, $\mathrm{OR}=11.14 ; \mathrm{CI}=2.35-52.75)$. Those people with HIV who used reminders tool (use of watch, mobile alarm and family members) for intake of medicine were 11 times more likely to report adherence to ARV therapy than those who did not use any reminders tool for intake of medicine. But, side effects and alcohol drink were not significantly associated with adherence to ARV therapy. 
Table 2. Multivariate analysis of adherence status and socio-demographic and patient related characteristics $(n=195)$

\begin{tabular}{|c|c|c|c|c|}
\hline Variables & $\begin{array}{l}\text { Crude } \\
\text { OR } \\
95 \% \text { CI }\end{array}$ & $\underset{\text { value }}{p}$ & $\begin{array}{l}\text { Adjusted } \\
\text { OR } \\
95 \% \text { CI }\end{array}$ & $\begin{array}{c}\mathbf{p} \\
\text { value }\end{array}$ \\
\hline \multicolumn{5}{|l|}{ Age } \\
\hline$\leq 38$ years & \multicolumn{2}{|l|}{1} & \multicolumn{2}{|l|}{1} \\
\hline$>38$ years & $\begin{array}{l}3.50 \\
(1.26- \\
9.72)\end{array}$ & $0.011^{*}$ & $\begin{array}{l}4.28 \\
(1.00- \\
18.26)\end{array}$ & $0.050^{*}$ \\
\hline \multicolumn{5}{|l|}{$\begin{array}{l}\text { Marital } \\
\text { status }\end{array}$} \\
\hline Married & $\begin{array}{l}4.96 \\
(1.67- \\
14.75)\end{array}$ & $0.002 *$ & $\begin{array}{l}0.47 \\
(0.11- \\
1.96)\end{array}$ & 0.301 \\
\hline Others & \multicolumn{2}{|l|}{1} & \multicolumn{2}{|l|}{ (2) } \\
\hline \multicolumn{5}{|l|}{$\begin{array}{l}\text { Monthly } \\
\text { family } \\
\text { income }\end{array}$} \\
\hline $\begin{array}{r}\text { Hardly } \\
\text { Sufficient }\end{array}$ & \multicolumn{2}{|l|}{1} & \multicolumn{2}{|l|}{1} \\
\hline Sufficient & $\begin{array}{l}7.04 \\
(2.48- \\
19.99)\end{array}$ & $0.000^{*}$ & $\begin{array}{l}2.25 \\
(0.44- \\
11.47)\end{array}$ & 0.329 \\
\hline \multicolumn{5}{|c|}{\begin{tabular}{l|l} 
Duration of \\
illness
\end{tabular}} \\
\hline$\leq 24$ months & \multicolumn{2}{|l|}{1} & \multicolumn{2}{|l|}{1} \\
\hline$>24$ months & $\begin{array}{l}3.79 \\
(1.33- \\
10.76)\end{array}$ & $0.008^{*}$ & $\begin{array}{l}3.77 \\
(0.80- \\
17.80)\end{array}$ & 0.093 \\
\hline \multicolumn{5}{|l|}{$\begin{array}{l}\text { Initiation of } \\
\text { ARV }\end{array}$} \\
\hline$\leq 24$ months & \multicolumn{2}{|l|}{1} & \multicolumn{2}{|l|}{1} \\
\hline$>24$ months & $\begin{array}{l}9.16 \\
(3.18- \\
26.38)\end{array}$ & $0.000 *$ & $\begin{array}{l}0.62 \\
(0.05-7 \\
65)\end{array}$ & 0.713 \\
\hline \multicolumn{5}{|l|}{$\begin{array}{l}\text { Source of } \\
\text { information }\end{array}$} \\
\hline $\begin{array}{r}\text { Health } \\
\text { personnel }\end{array}$ & $\begin{array}{l}10.24 \\
(3.08- \\
33.99)\end{array}$ & $0.000 *$ & $\begin{array}{l}4.23 \\
(0.62- \\
28.57)\end{array}$ & 0.138 \\
\hline Others & 1 & & 1 & \\
\hline
\end{tabular}

Table 4 shows that discrimination, help for the intake of medicine, adherence counselling and travelling cost were significantly associated with adherence to ARV therapy in bivariate analysis but
Table 3. Multivariate analysis of adherence status and patient related characteristics $(n=195)$

\begin{tabular}{|c|c|c|c|c|}
\hline Variables & $\begin{array}{c}\text { Crude } \\
\text { OR } \\
95 \% \\
\text { CI }\end{array}$ & $\underset{\text { value }}{p}$ & $\begin{array}{c}\text { Adjusted } \\
\text { OR } \\
95 \% \text { CI }\end{array}$ & $\begin{array}{c}p \\
\text { value }\end{array}$ \\
\hline \multicolumn{5}{|l|}{$\begin{array}{l}\text { Side effects of } \\
\text { ARV }\end{array}$} \\
\hline Yes & 1 & & 1 & \\
\hline No & $\begin{array}{l}3.90 \\
(1.11- \\
13.69)\end{array}$ & $0.023^{*}$ & $\begin{array}{l}6.72 \\
(0.79-5 \\
6.86)\end{array}$ & 0.080 \\
\hline \multicolumn{5}{|l|}{ Alcohol drink } \\
\hline Yes & 1 & & 1 & \\
\hline No & $\begin{array}{l}4.25 \\
(1.20- \\
15.07)\end{array}$ & $0.016^{*}$ & $\begin{array}{l}2.16 \\
(0.23- \\
19.06)\end{array}$ & 0.494 \\
\hline \multicolumn{5}{|l|}{$\begin{array}{l}\text { No. of tablets } \\
\text { daily }\end{array}$} \\
\hline$>3$ tablets & 1 & $0.013^{*}$ & 1 & \\
\hline$\leq 3$ tablets & $\begin{array}{l}6.53 \\
(1.73- \\
24.62)\end{array}$ & & $\begin{array}{l}10.72 \\
(1.21- \\
94.43)\end{array}$ & $0.032 *$ \\
\hline \multicolumn{5}{|l|}{$\begin{array}{l}\text { Remainders } \\
\text { tool used }\end{array}$} \\
\hline No & 1 & & 1 & \\
\hline Yes & $\begin{array}{l}4.94 \\
(1.77- \\
13.77)\end{array}$ & $0.001 *$ & $\begin{array}{l}11.14 \\
(2.35- \\
52.75)\end{array}$ & $0.002 *$ \\
\hline
\end{tabular}

they were not significantly associated with adherence to ARV therapy in multivariate analysis.

\section{DISCUSSION}

In this study, the status of adherence is subcategorised as Adherence and Non adherence. The majority of the respondents claimed not to have missed a single dose in the past one month, where $91.3 \% \quad(n=178)$ reported perfect/good adherence $(\geq 95 \%)$ and $8.5 \% \quad(n=16)$ of the respondents reported missing medications during the previous month (Non-adherence). The overall self-reported adherence rate for one month was $91.3 \%$. In this study the status of adherence to antiretroviral therapy, is slightly higher, and consistent to other similar studies in Nepal.4,6,7 This 
Table 4. Multivariate analysis of adherence status and psychosocial and service related characteristics

\begin{tabular}{|c|c|c|c|c|}
\hline Variables & $\begin{array}{c}\text { Crude } \\
\text { OR } \\
95 \% \\
\text { CI }\end{array}$ & $\begin{array}{c}p \\
\text { value }\end{array}$ & $\begin{array}{c}\text { Adjusted } \\
\text { OR } \\
95 \% \\
\text { CI }\end{array}$ & $\underset{\text { value }}{p}$ \\
\hline \multicolumn{5}{|l|}{ Discrimination } \\
\hline Yes & 1 & & 1 & \\
\hline No & $\begin{array}{l}3.90 \\
(1.11- \\
13.69)\end{array}$ & $\begin{array}{l}0.046 \\
*\end{array}$ & $\begin{array}{l}2.32 \\
(0.56- \\
9.57)\end{array}$ & 0.241 \\
\hline \multicolumn{5}{|l|}{$\begin{array}{l}\text { Help for intake } \\
\text { of medicine }\end{array}$} \\
\hline Yes & $\begin{array}{l}2.95 \\
(0.96- \\
11.54)\end{array}$ & $\begin{array}{l}0.050 \\
*\end{array}$ & $\begin{array}{l}1.55 \\
(0.40- \\
5.99)\end{array}$ & 0.523 \\
\hline No & 1 & & 1 & \\
\hline \multicolumn{5}{|l|}{$\begin{array}{l}\text { Adherence } \\
\text { counseling }\end{array}$} \\
\hline Yes & $\begin{array}{l}13.38 \\
(2.99- \\
59.75)\end{array}$ & $\begin{array}{l}0.002 \\
*\end{array}$ & $\begin{array}{l}4.91 \\
(0.84- \\
28.74)\end{array}$ & 0.077 \\
\hline No & 1 & & 1 & \\
\hline \multicolumn{5}{|l|}{ Travelling cost } \\
\hline Lower cost & $\begin{array}{l}3.99 \\
(1.40- \\
11.34)\end{array}$ & $\begin{array}{l}0.006 \\
*\end{array}$ & $\begin{array}{l}2.64 \\
(0.84- \\
8.28)\end{array}$ & 0.096 \\
\hline Higher cost & 1 & & 1 & \\
\hline
\end{tabular}

is compatible to several other studies conducted in developing countries like Uganda and Kenya where adherence rate of $89 \%$ and $82 \%$ have been reported, which were also based on self-reported adherence. ${ }^{8}$ In contrast to this, result of a study done in USA and Brazil showed the lower adherence rates to ARV therapy as $62 \%$ and $75 \%$ respectively. ${ }^{9}$

This study shows that ART adherence varied significantly by age $(\mathrm{OR}=4.28 ; \mathrm{CI}=1.00-18.26)$. Patients age greater than 38 years were four times more likely to report adherence to ARV therapy than those less than 38 years. Similar findings was found in American study by Barclay et al. showing the patients age greater than 40 years were two times more likely to adhere to ARV therapy. ${ }^{10}$ In contrast to this, the result of a study done in three hospitals of Kathmandu showed that increase in age by one year increased the risk of being nonadherent by $4 \%{ }^{6}$

In the present study, marital status showed a significant association with adherence to ARV therapy in bivariate analysis $(\mathrm{OR}=4.96 ; \mathrm{CI}=1.67$ 14.75). This implies that married people were 4.9 times more likely to report adherence to ARV therapy than those who were unmarried, separated/ divorced or widow/widower. This finding is consistent with the findings of the study done in Uganda. ${ }^{11}$ In contrast to this, the findings of the study done in Nepal, showed that marital status did not significantly influence adherence.6, 12

This study showed that patient's experience of medical side effects predicted non-adherence $(\mathrm{OR}=$ 3.90; $\mathrm{CI}=1.11-13.69)$ in bivariate analysis. The odd's ratio of adherence among those who did not experience side effects was 3.9 times higher than who reported experiencing medication side effects. This finding was consistent with findings of several other studies. ${ }^{3,7,13}$ In contrast, the study done in Kenyan showed that adverse effects did not significantly influence non-adherence. ${ }^{8}$

The assessment of pill burden in this study revealed that the number of pills taken per day was associated with the adherence in multivariate analysis $(p=0.032, O R=10.72 ; C I=1.21-94.4)$. The finding is consistent with the one Indian cohort study which showed that medication adherence increased by $100 \%$ in those on less than five tablets per day. ${ }^{14}$ In contrast to this, various studies reported that despite having the new regimens, 
fewer tablets and daily doses- adherence still remains a problem. ${ }^{15,16}$

In this study, use of reminders tool was significantly associated with adherence to ARV therapy $(\mathrm{p}=0.002, \mathrm{OR}=11.14 ; \mathrm{CI}=2.35-52.75)$ in multivariate analysis. The finding is consistent with the similar studies done in Nepal, which showed that use of remainders tool was significantly associated with adherence to ARV therapy and those who were more than $95 \%$ adherent responded used watch, electronic devices such as mobiles, watch and calendar to facilitate them to take the drugs regularly.6,7

In this study, experiencing no discriminations were the predictors of higher adherence in bivariate analysis $\quad(\mathrm{p}=0.046, \mathrm{OR}=3.90 ; \mathrm{CI}=1.11-13.69)$. People who experience no discrimination were 3.9 times more likely to report adherence than those who experience discrimination. The finding is consistent with the finding of similar study done in Kwazulu- Natal, South Africa, which showed that experiencing less discriminations were the predictor of higher adherence. ${ }^{17}$

In this study, significant association was observed between the adherence counselling and adherence to ARV therapy in bivariate analysis $(p=0.002$, $\mathrm{OR}=13.38 ; \quad \mathrm{CI}=2.99-59.75)$. Patients who got adherence counselling before initiation of ARV treatment were 13 times more likely to adhere to ARV therapy than those who did not get adherence counselling.

\section{CONCLUSIONS}

Based on the findings of the study and in light of the limitations of the study it can be concluded that the prevalence of adherence was found to be good. The finding suggests that age, side effects, alcohol use, lack of social support present additional barrier for adherence to ART. Whereas having reminders tools to take the pills and help from the family members enhanced adherence. Nevertheless, even within the context where free ART service is provided to HIV patients travelling cost or money spent to reach the ART centre remains an important barrier to adherence to HIV patients. Moreover, current finding demonstrates that in spite of universal access to ART, achieving perfect adherence remains a challenge with HIV \& AIDS and non- adherence remains a barrier to combat the epidemic.

To cite this article: Aryal N, Poudel R, Adhikari S, Rai A. Factors Associated with Adherence to Antiretroviral Therapy Among People Living With HIV \& AIDS. MJSBH. 2019;18(1):43-50.

Conflict of Interest: None declared

\section{REFERENCES}

1. National Center for AIDS and STD Control. Nepal Country Progress Report. Ministry of Health and Population. 2012; 5-8.

2. National Centre for AIDS and STD Control (NCASC). National Antiretroviral Therapy Guidelines. Government of Nepal; Ministry of Health and Population. 2012 May:22-4.

3. Wasti SP, Simkhada P, Van Teijlingen E. Antiretroviral treatment programmes in Nepal: problems and barriers. KUMJ. 2009; 7(3):306-14. 
DOI: https://doi.org/10.3126/kumj.v7i3.2743

4. Sharma S, Khadga P, Dhungana GP, Chitrakar U. Medication adherence to antiretroviral therapy among patients visiting antiretroviral therapy center at Tribhuvan University Teaching Hospital, Kathmandu Nepal. KUMJ. 2013; 41(1):50-3.

PMID: 23774414

5. World Health Organization (WHO). Fact sheet on HIV; WHO guidelines on HIV/AIDS. 2014.

6. Molassiotis A, Nahas-Lopez V, Chung WR, Lam SC, Li CP, Lau TJ. Factors associated with adherence to antiretroviral medication in HIV-infected patients. International journal of STD \& AIDS. 2002 May; 13(5):301-10.

DOI: https://doi/abs/10.1258/0956462021925117

7. Bam K, Karki DK, LohaniSP, Thapa R, Aryal UR, Pathak LR. Adherence to Anti- Retroviral Therapy among People Living with HIV and AIDS in Far West, Nepal. AJMS. 2011; 2(1):7-13.

DOI: https://doi.10.3126/ajms.v2i1.4290

8. Wakibi SN, W Ng'ang'a Z, Mbugua G. Factors associated with non-adherence to highly active antiretroviral therapy in Nairobi, Kenya. AIDS Research and Therapy. 2011 Dec;8(1):43.

DOI: http://hdl.handle.net/123456789/206

9. Beer L, Heffelfinger J, Frazier E, Mattson C, Roter B, Barash E, et al. Use of and Adherence to Antiretroviral Therapy in a Large U.S. Sample of HIV-infected Adults in Care, 2007-2008. Open AIDS J. 2012;6:213-23.

DOI: https:// doi: 10.2174/1874613601206010213

10. Barclay TR, Hinkin CH, Castellon SA, Mason KI, Reinhard MJ, Marion SD, et al. Age-associated predictors of medication adherence in HIV-positive adults: Health beliefs, self-efficacy, and neurocognitive status. Health Psychology. 2007 Jan; 26(1):40.

DOI: http://dx.doi.org/10.1037/0278-6133.26.1.40

11. Byakika-Tusiime J, Oyugi JH, Tumwikirize WA, Katabira ET, Mugyenyi PN, Bangsberg DR. Adherence to HIV antiretroviral therapy in HIV+ Ugandan patients purchasing therapy. International journal of STD \& AIDS. 2005 Jan;16(1):38-41.

DOI: http://doi/abs/10.1258/0956462052932548

12. Weiser S, Wolfe W, Bangsberg D, Thior I, Gilbert P, Makhema J, et al. Barriers to antiretroviral adherence for patients living with HIV infection and AIDS in Botswana. JAIDS. 2003 Nov;34(3):281-8. PMID: 14600572

13. Markos E, Worku A, Davey G. Adherence to ART in PLWHA and Yirgalem Hospital, South Ethiopia. EJHD. 2008;22(2):174-9.

DOI: https://www.ajol.info/index.php/ejhd/article/viewFile/10068/31342

14. Cauldbeck MB, O'Connor C, O'Connor MB, Saunders JA, Rao B, Mallesh VG, et al. Adherence to antiretroviral therapy among HIV patients in Bangalore, India. AIDS research and therapy. 2009 Dec;6(1):7 DOI: https://doi.org/10.1186/1742-6405-6-7

15. Erah PO, Arute JE. Adherence of HIV/AIDS patients to antiretroviral therapy in a tertiary health facility in Benin City. AJPP. 2008 Sep;2(7):145-52.

DOI: http://www.academicjournals.org/journal/AJPP/article-abstract/077C55732593

16. Aragones C, Sanchez L, Campos JR, Perez J. Antiretroviral therapy adherence in person with HIV/AIDS in Cuba. MEDICC Rev. 2011 Apr;13(2):17-23.

DOI: http://www.medigraphic.com/pdfs/medicreview/mrw-2011/mrw112e.pdf 
17. Bekalu MA, Eggermont S. The relative persuasiveness of gain-framed versus loss-framed HIV testing message: Evidence from a field experiment in northwest Ethiopia. Journal of health communication. 2014 Aug;19(8):922-38.

DOI: https://doi: 1471-2458/10/111 